\title{
Research on the Literature Teaching and Literature Education under the Exam-oriented Environment
}

\author{
Wei Xu \\ Shangluo University, Shangluo Shaanxi, 726000, China
}

\begin{abstract}
Keywords: Exam-oriented environment, Literature education, Literature teaching, Application measures
\end{abstract}

\begin{abstract}
With the further development of the educational system reformation in our country, all teaching and research institutions paid more and more attention to the literature education. However, for the interaction and amalgamation of literature education and literature examination, there is still distance, the interaction and amalgamation of literature education and literature examination is the demand of improving culture teaching level, also the demand of modern education career's adaption to social culture development. This paper combines the real situation of modern culture education, analyzes the application of literature education in the literature examination, presents feasible countermeasures for the contradictory problems in the literature teaching under the literature education horizon, to provide reference for researches of relevant work.
\end{abstract}

\section{Introduction}

In order to adapt to the needs of the development of society, examination mode of the literature teaching of our country has been made important adjustment, the improvement of requirement on the reading comprehension, the increase of thesis score and the improvement of requirement on the understanding and analysis on the thesis in the language test paper, is sufficient to certify that the function of literature education in the literature teaching is subtly displayed. Examination needs to make marking criterion, while literature education has outstanding non-standardization, it faces new challenge when the education gets progress and development. It is a problem worth further research of relevant education workers to carry out literature teaching and how to coordinate their influences and connections under the literature education horizon.

\section{Features of literature education}

Literature is a kind of art, while the biggest feature of art is its strong individuality, uncertainty and ambiguity. For example, each reader has his/her own understanding on a poem, that is an expression of literature art. If getting a same understanding through implanting awareness, literature will loss its inherent essential meaning. Therefore, these features made literature is "hard to learn, hard to teach and hard to examine". For a novel or an ancient poem, what teachers do is to explain its commonsense knowledge like source, background to lead students to get simple understanding on the work, thus to further understand and feel its inner artistry, the feeling of artistry of literary works needs students' own ability, it cannot be replaced by teachers.

How to evoke students' interest in a literary work under the situation of hiding personal emotions? How to inspire students to do reading comprehension? How to expand students' thinking way to help them make further exploration for a literary work? The most important is how to evaluate students' judge on literary works from a higher angle of art and literature history? All these are teaching abilities needed by a modern professional educators? At the present literature education, what teachers do is to make literal reading comprehension, lack of deep mater of the artistry of literary works.

Popularly speaking, literature education is to read, read carefully over and over again even very familiar with literary works, actually all these are just preparations for literature education, leading students to the word of art art through many artistic means to expand rich association can be called 
getting started of literature education; getting in and out of the literary works and acquiring civilization, improving literary attainment is the purpose of literature purpose.

\section{Function and actual application of literature brochure}

Functions of literature education in the literature teaching. Literature is a kind of education form to influence educatees according to their psychological demand to cultivate literature attainment and culture spirit by studying literary works. Literature education is called as education of "the true , the good and the beautiful", let educatees to have essential found that higher than reality, and also the improvement of the morality and human nature of educatees. Literature education is absolutely required lesson fir human beings, while in the former education system, the function of literature education was ignored, which is also the main reason that influenced people's attainment, aesthetic taste, ability to appreciate and writing ability.At present, reading comprehension and writing in the language test is related to literature education, lacking of literature education, reduce of students' reading ability and understanding ability are important factors that influence the result of the language test.Thus the function of literature education in the literature teaching is very important for the improvement of literature teaching quality.

Discuss the actual application of literature in the literature examination. In recent years, with the attention of literature education in literature teaching, during the process of daily examination and education, teaching institutions often use this method to observe students' literature attainment and literature level, thus also showed that under the background of exam-oriented education, literature education occupies an important place. It is also a key basis to balance students' quality, also, at present, many educators used literature in the examination, they think that the quality has a direct connection with quality-oriented education, this thinking is a little bit biased. We can say that literature level represents a student's literature analysis ability but cannot equal to quality-oriented education. Under the influence of education revolution, in the literature exam-oriented education, teaching contents in the Chinese textbooks has been increased a lot, while from the actual teaching, literature teachings in the textbooks are limited in analysis and are very trivial, it still has some distance to emotional education and aesthetic education; influenced by the Chinese textbook, for language paper of the college entrance examination, the proportion of essay reading and classical Chinese reading is increased, examination papers of many places over depends on literature, which is not benefit for the cultivation of modern talents.

\section{Application way of literature education in the literature teaching}

Under the guidance and education of teachers, students' literature attainment has been improved, this not only extends human civilization history, but also provides students with a lifelong benefit, thus the continuous strength of literature education in literature teaching promoted the good quality of students, help students improve their literature attainment, it is a necessary part of literature teaching. In the literature teaching, specific ways for application literature education are as follows:

Guide students to feel initially. In literature teaching, students realize the initial feeling of literary works under the guidance of teacher, and set this as the start of further exploration on literature. For a complete literature education progress, feeling of the literary works is the first step. The whole process of literature education is to feel, then understand and at last make judge. The initial feeling process of literary works is very important.

Encourage free understanding of students. Encourage students to freely express their own views and understandings on literary works. After students' initial feeling and understanding on literary works, teachers should guide students to make further analysis, this process should stimulate students make bold analysis and understanding on literary works. At this time, teachers cannot make clear judgment, should let students to understand by themselves. The essence of literary works cannot be taught by teachers but felt by students themselves. Students' understanding and appreciating ability is based on careful reading but not teachers' teaching. 
Correctly grasp literary images. In present literature exam-oriented teaching, there are many literary works in the textbooks, the referred stylistic range type is more and more broad. These literary works normally are described vividly, express rich emotions, are easy to attract readers. During teaching, how to grasp literary images, and use right points to make analysis that students can express thought with images and acquire education enlightenment from it.

Use connotation, feel emotion, create form practice. When appreciate a literary work, use rich connotation to analyze the article structure, to feel the emotional world expressed by the author, the more important thing is to guide students to create based on the model essay. On one hand, it is a comprehensive expression of students' grasp of language and their ability to use language, on the other hand, it is also the comprehensive reflection of students' literature attainment. Therefore, during the writing process, teachers should to cultivate right views, healthy ideological ethics and noble quality accomplishment of students. Help students improve their own ideological understanding and analysis ability. To help students get into society, get into life catch sense of beauty and express from the essay.

Design and organize activities. Through all kinds of language teaching activities organized by teachers to carry out literature education, receive edification, leave students with deepest impression. Teachers should combine teaching reality and experience to organize diversified teaching activity, motivate students' passion through vivid performances to improve their enthusiasm for language learning to achieve the purpose of purpose of improving students' literature attainment and appreciation ability. Organize students to carry out the second class, to help students inspired by the literary works through careful reading.

\section{Measures to strengthen literature education in literature teaching}

At present, in the literature teaching of different schools, most of the selected articles are literary works, the cognition and experience of the artistry value and application value of this kind of literary works becomes key contents of teaching and studying. Inheriting aesthetic education is the function of literary works, readers can realize improvements on language, emotion and thoughts by reading literary works. Teachers influences and edifies students through rich emotion and deep thoughts. Help students to feel the charm of language and enjoy the enlightenment brought by literary works during the process of contacting with literary works.

Improve educators' literature attainment. Literature attainment means the quality of literary theory and the feeling and judging ability for literary works and the literary creation ability. Among present literature teaching, the selected literary works are not only with rich connotation and will influence the values orientation and emotional attitude. In the real teaching process, the inspiring teacher must have noble literature attainment and literature details, that can understand the choreography intentions of textbook, and dig the connotation of literary works, to understand different textbook expressions and unified with the spirit of the literary work and build a bridge to connect literary works and the educatees.

Improve teachers' literature attainment through changing concept, strengthen reading accumulation and improving creative ability, teachers should attract students with good contents, and integrate literature in their education to form a new teaching thinking. The improvement of teachers' literature attainment has positive function on the culture and quality-oriented education.

Improve reading ability, improve literature attainment. Under the same condition, literature attainment is determined by students' reading ability, improving reading ability is benefit to improve enrich culture and knowledge to improve literature attainment. Literature education is also called as aesthetic education, it is the specific expression of students' feeling on literary images, tasting language charms to improve students' appreciation ability for literary works. The key object of literature education is to let students accept the felling brought by literary works and to construct their emotion and live experience. In order to realize objects of literature education, students must read more and read good books. Reading quantity and quality is the main factor affecting the formation of literature attainment. Teachers should carry out education through readings on literary works. Motivate the reading interest of students to help them acquire further understanding and application 
of letters, cultivate students' ability of fast reading and knowing the real meaning of literary works. Under the edification of literary works, students' thinking can be more deep and broad.

Strengthen practices, improve literary attainment. Today's literature teaching pays much attention to the cultivation of literature attainment of students, the language study has strong practicability, should take the nurturing of students' practical ability as key point. Widely carry our language teaching activities, explore its regulation, strengthen the writing practice and improve literature attainment.

\section{Organic integration of literature examination and literature education}

Under the new situation of educational revolution and development, literature examination and literature education are gradually integrated organically. In the former education system, the influence of literature education on students mainly based on their own willing, it was a little bit different from literature examination on the form. While the influence of literature examination teaching on students are normally on the technical level, it over strengthened the logical understanding of letters, words, sentences and the grasp of method, but neglected the understanding and communication on the literary works, which greatly decreased the original value of the literary works. In recent years, the setting of new curriculum standard improved the integration degree of literature examination and literature education, gradually realized their integration.

New curriculum standard not just strengthen the practicality and humanity of the literature teaching on the concept, the aesthetic function of literature teaching also is strengthened. Continuously to enlarge the literary works range and improve the place of literary works. Changing the former unchanged basic skills evaluation standard to students' real feeling on literary works is a big progress in literary teaching development. Optional courses should emphasize students' reading points, improve students' attention on the real evaluation on literary works, cultivate students' unique feeling and individual understanding on literary works, advocate and encourage creative reading and individual reading forms. Set students' aesthetics ability, appreciation individuality and art interests as the evaluation criterion of optional courses. In recent years, with the design and implementation of new evaluation criterion, language teat papers changed a lot, especially the individual expression and evaluation on the literary works reading and understanding are all real expression of the essential object of literature education.

\section{Conclusion}

All the signs showed that the development of literature teaching and literature education is linked to each other, no one can be shorted in the cultural education system. In the present literature teaching, the position of literature education is gradually prominent, and gradually permeates in every detail of literature teaching, and promoted the reform of cultural education system. Under the new situation of the continuously perfecting and development of education system, to realize the guidance, influence and education for students with the power of literature education in the literature teaching, combine literature teaching and literature education perfectly, final to realize the healthy and orderly development of education.

\section{References}

[1] Zhang Xiaomei. Discussion on the Literature Education in the Language Teaching in the Primary School. Style Products and Technology, 2011,12:148.

[2] Li Shanshan. Research on the Education Practice of Poems in High School Chinese.Yangzhou University,2014.

[3] Cai Benjia of the National High School in Qinghai Province. Analysis on the Contradiction between Literature Education and Literature Teaching. Leaning News,2011-04-18H04.

[4] Zhang Jingyi. Investigation and Analysis on the Literature Reading and Teaching Goal Design of Language Teachers in High Schools. Education and Teaching Research,2014,06:107-110. 